\title{
REFLEXÕES ACERCA DO PERFIL DE ATENDIMENTO NA ESTRATÉGIA SAÚDE DA FAMÍLIA
}

\author{
Letícia de Lima Trindade ${ }^{1}$, Andressa Peron², Simone Coelho Amestoy ${ }^{3}$, Graciela Cabreira Gehlen ${ }^{4}$, Patrícia
} Tuerlinckx Noguez ${ }^{5}$

\begin{abstract}
RESUMO: O presente trabalho teve como objetivo refletir sobre as ações de cinco equipes de Estratégia Saúde da Família de um município do interior de Santa Catarina, a partir das informações contidas no seu relatório anual. Reflete-se que o trabalho das equipes permanece voltado para o modelo biomédico, embora o estudo revele alguma importância para o trabalho multidisciplinar, a consulta de enfermagem, as ações dos agentes comunitários de saúde na formação dos laços com a comunidade e as atividades de educação em saúde para romper com o modelo biologicista de atenção à saúde. Percebe-se a necessidade de investimentos na formação dos profissionais com a formulação de ambientes para a socialização e reflexão sobre o trabalho no modelo assistencial apontado pela Estratégia Saúde da Família.
\end{abstract}

PALAVRAS-CHAVE: Enfermagem; Programa saúde da família; Saúde da família; Sistema único de saúde.

\section{REFLECTIONS ON THE SHAPE OF ATTENDANCE IN THE FAMILY HEALTH STRATEGY}

\begin{abstract}
This work aims to reflect on the actions of five teams working with the Family Health Strategy in a county in the interior of the state of Santa Catarina, going by the information contained in their annual report. It observes that the teams' work continues to be based on the biomedical model, although the study shows that multidisciplinary work, nurse consultations, the actions of community health workers in forming links with the community and health education activities are all of some importance in breaking with the biological model of health care. One can see the necessity for investment in the forming of professionals through the shaping of environments for socialisation and reflection on the work done with the assistential model aimed at by the Family Health Strategy.
\end{abstract}

KEYWORDS: Nursing; Family health program; Family health; Single health system.

\section{REFLEXIONES ACERCA DEL PERFIL DE ATENDIMIENTO EN LA ESTRATEGIA SALUD DE LA FAMILIA}

RESUMEN: Este trabajo tuvo como objetivo reflexionar acerca de las acciones de cinco equipos de Estrategia Salud de la Familia de un municipio del interior de Santa Catarina, con base en las informaciones contenidas en informe anual. Se observó que el trabajo de los equipos se relaciona al modelo biomédico, a pesar de que el estudio revele alguna importancia para el trabajo multidisciplinar, la consulta de enfermería, las acciones de los agentes comunitarios de salud en la formación de los vínculos con la comunidad y las actividades de educación en salud para romper con el modelo biologicista de atención a la salud. Se percibe la necesidad de inversiones en la formación de los profesionales con la formulación de ambientes para la socialización y reflexión acerca del trabajo en el modelo asistencial apuntado por la Estrategia Salud de la Familia.

PALABRAS CLAVE: Enfermería; Programa de Salud Familiar; Salud de la familia; Sistema único de salud.

\footnotetext{
${ }^{1}$ Enfermeira. Doutoranda do Programa de Pós-Graduação em Enfermage da Universidade Federal de Santa Catarina-UFSC. Membro do Grupo de Pesquisa Práxis UFSC. Professora da Faculdade de Pato Branco-FADEP e do Centro Universitário Católico do Sudoeste do Paraná.

${ }^{2}$ Enfermeira. Especialista em Saúde da Família.

${ }^{3}$ Enfermeira. Doutoranda do Programa de Pós-Graduação em Enfermagem da UFSC. Bolsista CNPq. Membro do Grupo EDEN UFSC. ${ }^{4}$ Enfermeira. Doutoranda do Programa de Pós-Graduação em Enfermagem da Universidade Federal do Rio Grande do Sul-UFRGS. Professora e Coordenadora do Curso de Graduação em Enfermagem da FADEP.

${ }^{5}$ Enfermeira. Mestre em Enfermagem. Professora do Curso de Graduação em Enfermagem da FADEP e da Universidade do Oeste de Santa Catarina.
}

Autor Correspondente:

Letícia de Lima Trindade

Faculdade de Pato Branco

R. Caramuru, 599 - 85501060 - Pato Branco-PR-Brasil

Recebido: $18 / 01 / 10$

E-mail: letrindade@hotmail.com

Aprovado: 10/09/10 


\section{INTRODUÇÃO}

Em busca da expansão e consolidação do Sistema Único de Saúde (SUS) foi implantado, em todo o território nacional, o Programa de Saúde da Família (PSF), que teve início no ano de 1994 e vem apresentando um crescimento expressivo nos últimos anos ${ }^{(1)}$.

O PSF, hoje chamado de Estratégia Saúde da Família (ESF), tem como intuito fomentar mudanças na política de saúde vigente, por meio da implantação de equipes multidisciplinares que atuam no âmbito da promoção da saúde, prevenção, recuperação, reabilitação de doenças e agravos mais frequentes. Essa estratégia emerge no sentido de organizar a expansão e a qualificação da atenção básica, na busca de superar o antigo modelo assistencial centrado na doença, tendo como princípios fundamentais a integralidade, qualidade da assistência, equidade e participação social.

Diante disso, objetivou-se construir um estudo reflexivo acerca das ações das equipes da ESF de um município do interior do Estado de Santa Catarina, a partir do perfil das ações dessas equipes registradas no relatório municipal de 2008.

\section{O perfil das ações da ESF}

O município no qual se realizou o estudo está situado na região Noroeste de Santa Catarina e se caracteriza como de pequeno porte (cerca de $21 \mathrm{mil}$ habitantes). A rede pública de atendimento à saúde conta com um hospital filantrópico conveniado ao SUS, Serviço Móvel de Atendimento de Urgência e Emergência e cinco equipes da ESF, cuja implantação teve início em 1998. Todas as equipes seguem o quadro mínimo prescrito pelo Ministério da Saúde (um médico, um enfermeiro, um técnico em enfermagem e de quatro a seis agentes comunitários de saúde-ACS).

A partir dos dados fornecidos pelos relatórios de atendimentos do município, do ano de 2008, constatou-se que as equipes da ESF realizaram um total de 22.571 consultas médicas, 15.165 consultas de enfermagem, 469 reuniões e/ou grupos com a comunidade, 1.459 visitas domiciliares (VD) realizadas pelos médicos, 1.724 VD feitas pelos enfermeiros, 2.095 VD realizadas pelos técnicos em enfermagem e 42.074 visitas realizadas pelos ACS. Ainda, foram realizados 7.375 procedimentos técnicos, que incluíram todos os procedimentos de enfermagem e as suturas médicas.

Nesse contexto, e com referência na literatura pesquisada sobre o perfil das ações a serem prestadas pelos profissionais da ESF, buscou-se refletir sobre o caráter da assistência prestada. Os critérios analisados foram o atendimento médico e de enfermagem, as atividades de educação em saúde e as visitas domiciliarias.

\section{Supervalorização da consulta médica}

Ao analisar os dados, percebe-se que o atendimento das equipes da ESF ainda se mantem centrado na consulta médica, levando-se em conta a alta demanda por esse serviço no município.

De acordo com o modelo da ESF, a assitência busca ampliar o modelo clínico de atenção à saúde que focaliza suas ações na patologia e na cura. Além disso, o médico de família deve ser capacitado para observar as complexas condições que envolvem o processo saúde-doença, e não somente as condições biológicas dos indivíduos. Deve ser capaz de focalizar as ações para o indivíduo e sua coletividade, ao considerar a importância do meio em que ele vive e o seu núcleo familiar ${ }^{(2)}$.

Diante disso, o acolhimento se coloca como uma estratégia para conhecer e atender as reais demandas/necessidades da população, e deve constituir-se como uma marca de todos os trabalhadores que integram a ESF. Autores defendem que o acolhimento propõe inverter a lógica de organização e funcionamento do serviço de saúde, tendo como princípio atender a todas as pessoas que procuram os serviços de saúde e garantir a acessibilidade universal ${ }^{(3)}$. Desse modo, os profissionais de saúde devem escutar e dar uma resposta positiva, capaz de resolver os problemas de saúde da população. Ainda, o acolhimento possibilita reorganizar o processo de trabalho, a fim de que este desloque seu eixo central do médico para uma equipe multiprofissional. Torna possível, ainda, qualificar a relação trabalhador-usuário que deve dar-se por parâmetros humanitários de solidariedade e cidadania.

Nesta perspectiva, a política de humanização da atenção à saúde vem discutindo a proposta da clínica ampliada como um instrumento no qual os trabalhadores e gestores de saúde possam perceber e atuar de forma a reconhecer e utilizar o potencial desse saber. A ideia central desta proposta é lidar com os usuários enquanto sujeitos, buscando sua 
participação e autonomia no processo terapêutico ${ }^{(4)}$.

\section{A consulta de enfermagem no contexto da ESF}

O estudo mostrou um elevado número de consultas de enfermagem quando considerados o total de procedimentos contidos no relatório, o número de equipes da ESF e a população do município em questão. A consulta de enfermagem é vista no âmbito do SUS como uma importante ferramenta para aumentar a qualidade da assistência à saúde da população.

O enfermeiro da ESF utiliza a consulta de enfermagem que, em tese, deve contribuir para superar o processo de atendimento sob a ótica do modelo biomédico e estabelecer relações de vínculos entre os indivíduos com o intuito de identificar as situações de risco mais amplas (social, psíquico, entre outros) para o planejamento de ações, e prestar uma assistência qualificada e integral aos usuários ${ }^{(5)}$. A consulta de enfermagem é considerada uma atividade autônoma, pela qual o profissional tem a possibilidade de estabelecer laços consistentes com o cliente. Pode fornecer dados relevantes, não somente a respeito de sua condição física momentânea, como abrir espaço para outras dimensões merecedoras de atenção.

$\mathrm{Na}$ ESF, o enfermeiro desenvolve uma extensa gama de atividades, as quais incluem o atendimento direto à população, a consulta de enfermagem, as ações de educação em saúde, o gerenciamento do serviço, entre outras. Por tudo isso, o enfermeiro se apresenta como um profissional indispensável, assumindo variadas e complexas atividades na ESF.

\section{As atividades de educação em saúde}

As reuniões e atividades em grupo representam um importante espaço para se produzir o diálogo, não somente com a comunidade, mas também com o indivíduo. Entretanto, na realidade estudada, essas oportunidades aparecem com pouca frequência, ocorrendo em proporção menor do que as demais atividades. Infelizmente, o relatório não informa os motivos do número reduzido dessas atividades, e assim não permite a análise das dificuldades enfrentadas para o desenvolvimento das mesmas.

Os grupos e outras atividades de educação em saúde podem significar estratégias de promoção à saúde que ampliem o foco dos cuidados para além da preocupação com a doença, podendo resgatar aspectos importantes para estimular a autonomia dos indivíduos e transformar a realidade social.

Acredita-se que as ações de educação em saúde devem estimular a organização comunitária e a autonomia das famílias, tendo em vista que o modelo assistencial proposto é o de privilegiar a promoção da saúde, o que se baseia no encorajamento e apoio para que as pessoas e grupos sociais assumam maior controle sobre os determinantes de saúde, o que se convencionou chamar de empoderamento para a ação social $^{(6)}$

Outro desafio das equipes é saber utilizar, de maneira mais adequada, os momentos de encontro com o usuário, quando o profissional, além de realizar procedimentos técnicos, pode utilizar-se dessa situação para acolher demandas, formar vínculos e otimizar as relações humanas ${ }^{(7)}$. As atividades de educação em saúde devem provocar mudanças de hábitos de vida dos usuários do SUS que favoreçam o autocuidado, uma vez que a educação em saúde busca a resignificação da consciência social, de hábitos e comportamentos $^{(8)}$.

\section{As visitas domiciliares}

Outra forma preconizada pela ESF para trabalhar a educação em saúde é fortalecer os vínculos da equipe com os usuários, por meio das visitas domiciliares, reconhecidas como uma importante ação em saúde para promover a modificação do modelo tradicional de atendimento. Na realidade em estudo, constatou-se um bom número de visitas realizadas pelo médico, pelo enfermeiro e pelos ACS. Entretanto, o relatório não permite conhecer se as VD são realizadas individualmente, por mais de um membro da equipe ou pela equipe toda.

Com a VD, que é forma privilegiada de instrumentalizar a inserção e o conhecimento da realidade de vida da população pelos membros da equipe de saúde, busca-se atender as diferentes necessidades sociais (individuais e coletivas), levando em conta a infraestrutura local ${ }^{(8)}$. Compreende-se, aí, principalmente os contatos com as lideranças comunitárias, os informantes-chave e as organizações/associações. Vale lembrar que um dos princípios do SUS é a participação social. Entende-se a participação popular como uma prática social que supõe a participação das classes sociais, principalmente a dos trabalhadores, em todos os níveis de organização da sociedade. Entretanto, essa participação deve se dar de forma organizada, envolver associações, comitês, fóruns, 
conselhos, sindicatos, partidos, movimentos e organizações, dentre outros mecanismos, nos diferentes esferas de organização do Estado e nas diferentes áreas de atuação ${ }^{(9)}$.

Quanto ao trabalho do ACS, cabe a esse realizar atividades de prevenção de agravos e promoção da saúde, por meio de ações educativas, realizadas em domicílios ou em espaços organizados, ou não, da coletividade. Contudo, observa-se que, por vezes, o ACS atua em condições desfavoráveis para o adequado desenvolvimento das atividades e do desempenho de suas competências, incluindo ambientes de trabalho inadequados e que favorecem seu adoecimento ${ }^{(10)}$.

Dentre os aspectos limitadores e desgastantes no trabalho do ACS, destacam-se: a falta de reconhecimento do poder público; problemas socioeconômicos das famílias; problemas com a própria saúde; falta de capacitação e de reconhecimento profissional; e falta de instrumentos e de tecnologias para suprir as necessidades do seu trabalho nas suas diferentes dimensões. Essas limitações dificultam a operacionalização do trabalho do ACS com ênfase na integralidade do cuidado $^{(11)}$ e são desfavoráveis também à saúde desses trabalhadores.

Por fim, no cuidado domiciliar, uma das ações centrais da VD, a família passa a ser um elemento que, além de interagir e participar na definição de padrões de cuidado, deve ser levada a promover sua própria saúde, e torna-se agente do próprio cuidado ${ }^{(12)}$.

\section{CONSIDERAÇÕES FINAIS}

A partir dos achados deste estudo, vê-se que é preciso repensar os pontos que indicam fragilização no respeito aos princípios da ESF, tais como o processo de trabalho muito focado na consulta médica, a dificuldade em trabalhar com a educação em saúde e a tímida realização das ações de estímulo à participação social. Mesmo passados mais de vinte anos da instituição do SUS e quinze anos da implantação das primeiras equipes da ESF, o modelo assistencial ainda continua articulado em torno da consulta médica, priorizando a atenção à doença.

A ESF propõe ir além do paradigma centrado na enfermidade e na hospitalização, passando para uma concepção mais ampla de saúde. Além disso, a ESF deve estimular a organização comunitária e a autonomia das famílias, ou seja, empoderar os sujeitos, visto que o modelo assistencial proposto é o da promoção da saúde, que é baseada no encoraja- mento e apoio para que as pessoas e grupos sociais assumam maior controle sobre sua saúde.

Como decorrência do que foi exposto, destaca-se a necessidade de maiores investimentos na formação e condição de trabalho dos profissionais para operar na ESF, bem como a intensificação de ambientes de debate sobre as condições sociais e da reflexão sobre os compromissos desse modelo assistencial.

\section{REFERÊNCIAS}

1. Ministério da Saúde (BR). Programa Saúde da Família. Brasília: Ministério da Saúde; 2001.

2. Ermel RC, Fracolli LA. O trabalho das enfermeiras no Programa de Saúde da Família em Marília/SP. Rev Esc Enferm. USP. 2006;40(4):533-9.

3. Franco TB, Bueno WS, Merhy EE. O acolhimento e os processos de trabalho em saúde: o caso de Betim, Minas Gerais, Brasil. Cad Saúde Pública. 1999;15(2):345-53.

4. Fracolli LA, Zoboli ELCP. Descrição e análise do acolhimento: uma contribuição para o Programa de Saúde da Família. Rev Esc Enferm USP. 2004;38(2):14351 .

5. Santos SMR, Jesus MCP, Amaral AMM, Costa DMN, Arcanjo RA. A consulta de enfermagem no contexto da atenção básica de saúde. Texto Contexto \& Enferm. 2008;17(1):124-30.

6. Costa GD, Cotta RMM, Ferreira MLSM, Reis JR, Franceschini SCC. Saúde da família: desafios no processo de reorientação do modelo assistencial. Rev Bras Enferm. 2009;62(1):113-8.

7. Hildebrand SM, Shimizu H. Percepção do agente comunitário sobre o programa família saudável. Rev Bras Enferm. 2008;61(3):319-24.

8. Giacomozzi CM, Lacerda MR. A prática da assistência domiciliar dos profissionais da estratégia de saúde da família. Texto Contexto \& Enferm. 2006;15(4):645-53.

9. Oliveira ML, Almeida ES de. Controle social e gestão participativa em saúde pública em unidades de saúde do município de Campo Grande, MS, 1994-2002. Saúde Soc. 2009; 8(1):141-53

10. Trindade LL, Gonzales RMB, Beck CLC, Lautert L. Cargas de trabalho entre os agentes comunitários de saúde. Rev Gaúch Enferm. 2007;28(4):473-9. 
11. Oliveira AR, Chaves AEP, Nogueira JA, Sá LD, Collet N. Satisfação e limitação no cotidiano de trabalho do agente comunitário de saúde. Rev Eletr Enf. 2010;12(1):28-36.

12. Ribeiro LCC, Ribeiro M, Dias KS, Matos KA, Ferreira TSA. O diagnóstico administrativo e situacional como instrumento para o planejamento de ações da Estratégia de Saúde da Família. Cogitare Enferm. 2008;13(3):448-52. 